\title{
Mental health awareness campaign exposes challenges in combatting stigma
}

A wareness campaigns for specific diseases and medical issues can be limited in scope, but when it comes to mental health, simply talking about the heavily stigmatized topic seems to help normalize it.

The third annual "Bell Let's Talk Day" campaign came to a close on Feb. 12, with Canadians participating in more than 96 million long distance phone calls, texts, tweets and Facebook shares to help raise awareness for mental health. Bell donated 5 cents for each of these communications, which added an additional $\$ 4.8$ million for mental health programs nationwide - a $23 \%$ increase over last year's campaign total.

"With mental illness there is that unique stigma that goes with it as well, and the way that we have to counter the stigma is by getting people talking about it," says Dr. Phil Ritchie, a child psychologist at the Children's Hospital of Eastern Ontario (CHEO).

"Wouldn't it be wonderful when we no longer have to have the [Bell Let's Talk] day because talking about mental illness is just something that we take for granted, it's just something that we'll do and people would feel comfortable just mentioning it as they would anything else?"

This "unique stigma" is particularly apparent in Canada, where $27 \%$ of the population is reportedly fearful of being around an individual who suffers from serious mental illness, according to the Canadian Medical Association's 8th Annual National Report Card on Health Care (www.cma.ca/multimedia/CMA /Content_Images/Inside_cma/Annual _Meeting/2008/GC_Bulletin/National _Report_Card_EN.pdf).

"What the stigma does is it robs people of having a support network when they're dealing with this illness," says Benjamin Leikin, mental health project officer at Ottawa Public Health.

"It delays access to treatment so individuals who are dealing with a mental

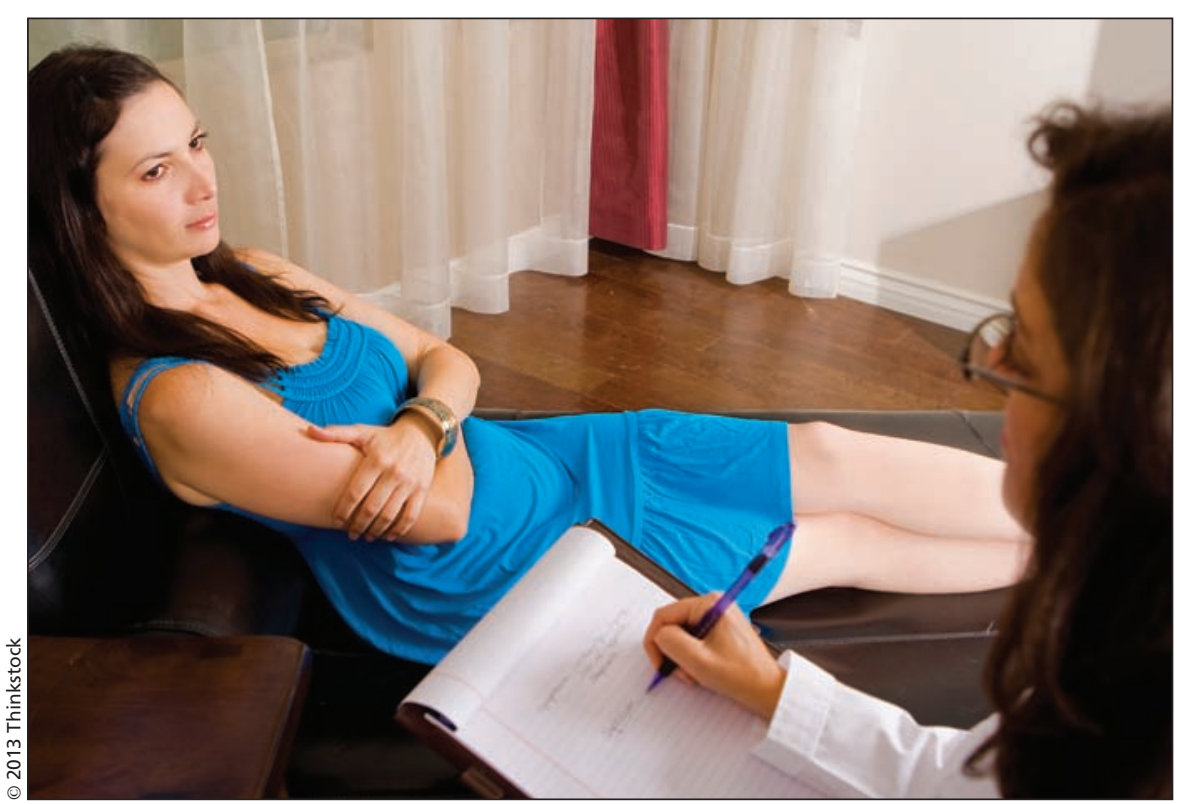

People with mental health issues would likely seek care much sooner if not for the stigma that continues to linger around mental illness.

illness may not feel comfortable might feel ashamed, embarrassed, afraid — to tell their doctor or someone about what they're going through and in that time they're not getting the treatment or the support they need for that illness."

In addition to bringing mental health issues to the forefront, the money raised in the campaign will help fund a variety of mental health services and initiatives across Canada.

"It goes to small agencies, some larger agencies and some to universities to continue to both provide services and provide opportunities to communities that may not have the funding they need," says Dr. Rajiv Bhatla, the Royal Ottawa Hospital's chief of psychiatry.

The campaign is more far-reaching in scope than other initiatives that deal with specific medical issues such as breast cancer or heart disease, in the sense that it is taking a broader approach to mental health awareness, he adds.

Although the campaign is "helping to bring this subject out of the darkness," says Leikin, “... there would be a risk in thinking that this in itself is enough. This is definitely a good starting point and this is a great lead off for us as a community, as a country, to continue this topic."

Experts say the issue is particularly important given one in five Canadians will experience a mental illness at some point in their lives, according to the Canadian Mental Health Association.

"When you start to plot that you realize that what this really means is that all of us have someone in our families or someone really close to us that is affected. ... It's not an 'us and them' kind of issue — it's all of us," says Ritchie.

In order to take pressure off the hospital system, alternative types of care need to be embraced, says Leikin, including community-based mental health organizations such as the Canadian Mental Health Association or local health and resource centres across Canada.

The Bridges Project is a new endeavour being formed by the Royal Ottawa 
Hospital, Public Health, CHEO and the Youth Services Bureau of Ottawa to improve community-based care by providing intensive treatment outside of the hospital setting based on adolescents' needs.

"It is a challenge because there are just so many new cases presenting every day so it is creating a bottleneck effect at the emergency rooms," says Leikin.
"We're trying to ensure that when people are in a time of need that there's a service there for them, and also letting people know that it's not always an in-patient unit within a hospital that might be able to serve them best."

As people discuss mental health on a more regular basis, more pressure can be put on the system to provide for those in need, says Ritchie.
"All of us have to look at how we offer our services, and how we can coordinate things differently," says Ritchie. "But we'd far rather have that as a problem, than people not asking the questions and having young people killing themselves." - Adam Miller, CMAJ

CMAJ 2013. DOI:10.1503/cmaj.109-4415 